\title{
Las Ideas en la América del Sur Sobre la Ilustración Española
}

$\mathrm{E}$ N los últimos años se han llevado a cabo numerosas investigaciones tendientes a demostrar la presencia en la España del siglo XVIII de un movimiento paralelo al de la Ilustración existente en otros países europeos. Es éste un tema sumamente discutible. Para muchos observadores de hoy, como para los del siglo dieciocho, el ambiente intelectual de la España de entonces se puede resumir en el caústico comentario de Voltaire: "Il y faut demander permission de penser à un capucin"..1

No me voy a ocupar aquí de las polémicas provocadas por Masson de Morvilliers, quien preguntaba en la Encyclopédie methodique, "Que doit-on à l'Espagne".2 Lo que me propongo, en cambio, es examinar la actitud de algunos pensadores de la América del Sur* entre los años de I790 y 1830 , ante el problema que semejante pregunta planteaba.

Estos hombres se expresaron del mismo modo que Rousseau, Voltaire y Thomas Paine, revelando claramente que estimaban en muy poco el valor intelectual de la cultura española de su época. La actitud extremadamente desdeñosa que manifestaron con respecto a su herencia española, está completamente en desacuerdo con las conclusiones de los eruditos del siglo veinte que suponen la existencia activa de un movimiento de la Ilustración en España. De los datos que vamos a presentar resulta evidente que la denuncia de la política colonial española no se limitó a la de los poco informados philosopbes franceses e ingleses que escribian bajo la influencia del abate Raynal. En cambio, los más severos críticos

* Decimos América del Sur y no América Hispánica, Iberoamérica o América Latina, porque en este trabajo no se incluyen México ni los países de la América Central en el tratamiento del tema.

1 Citado en Mario di Pinto, Cultura spagnola nel settecento (Napoli, 1964), p. 183. Véase también A. O. Aldridge, "The Cloudy Spanish Enlightenment," Modern Language Journal, LII (Feb. 1968), pp. 113-116.

2 Encyclopédie méthodique (Paris, 1782-1832), Géographie moderne, Tome I, pp. 554-586. 
de la censura española fueron los hombres de la primera generación de pensadores libres en la América del Sur, quienes por haber vivido bajo el régimen colonial español sabían, seguramente, cuál había sido la situación en esos territorios.

El gran contraste entre el ambiente filosófico verdaderamente progresista de la América del Sur desde I790 a I830 y el de España de I700 a 1800 indica que el primero dificilmente pudo haberse derivado del segundo. En otras palabras, los pensadores españoles del siglo dieciocho parecen haber influido muy poco en la aparición de los ideales de la Ilustración en las colonias españolas. Fueron Montesquieu, Rousseau, Voltaire y Thomas Paine, más que Feijóo, Torres Villarroel o Cadalso los responsables de la Ilustración en la mayor parte de Latinoamérica.

Puede alegarse que, en general, la Ilustración terminó en 1800 y que el período que va de I800 a I830 debe ser considerado en la América del Sur como el de la Revolución Liberal; pero debe tenerse en cuenta que los escritores latinoamericanos de entonces consideraban dicho período como parte de la IIlustración. Véase, por ejemplo, la declaración: "Estamos en el siglo de las luces..." en El Observador Eclesiástico, 1823,3 y, en el mismo año, el juicio de Camilo Henríquez, quien consideraba que la ocupación napoleónica de España era parte de la "nueva aurora de la ilustración".4

Cualquier crítica adversa al modo en que España administró su imperio colonial se ha resumido tradicionalmente bajo el rótulo de la Leyenda Negra. La leyenda se inició tempranamente con la Breuśsima Relación de la destrucción de las Indias (1552) de Bartolomé de las Casas, conquistador él mismo que ingresó en la Orden de los dominicos y denunció la tiránica audacia con que los explotadores trataban a los indios indefensos. Ya desde los tiempos de Las Casas se hizo un esfuerzo enorme para desacreditar estas acusaciones.5 La expresión "Leyenda Negra" ha servido también para impugnar a Las Casas y a cada uno de los posteriores críticos del colonialismo español. La Inquisición en México fue aún más

3 El Observador Eclesiástico, No. 1, 21 de junio de 1823. Reimpreso de la Colección de antiguos periódicos chilenos, ed. Guillermo Feliú Cruz (Santiago, 1963), XIV.

4 Mercurio de Chile, No. 23, 13 de marzo de 1823. Reimpreso de la Colección de antiguos periódicos chilenos (Santiago, 1960), IX. Véase también A. O. Aldridge, "Apostles of Reason: Camilo Henriquez and the French Enlightenment," Studies on Voltaire anl the Eighteenth Century, LV (1967), 65-87.

$5 \mathrm{La}$ historia de esta leyenda se puede encontrar en las obras siguientes: Lewis Hanke, Bartolomé de las Casas, Bookman, Scbolar and Propagandist (Philadelphia, 1952); Ramón Menéndez Pidal, El P. Las Casas y Vitoria (Madrid, 1958); Sverker Arnoldsson, La leyenda negra: estudios sobre sus origenes. Actra Universitatis Gotboburgensis. Göteborgs universitets ärsskrift, v. 66, 1960: 3. 
lejos y sostuvo que el libro de Las Casas sobre la destrucción de las Indias era falso y no había sido escrito por Las Casas sino por un francés. ${ }^{6}$ Para destruir la Leyenda Negra se instituyó una Leyenda Gris, según la cual el gobierno español sancionó leyes justas y sabias para proteger a los indios y la Iglesia Católica consideró a los indios y a sus señores españoles espiritualmente iguales.

La obra de Las Casas no puede incluirse dentro del período de la Ilustración por la fecha en que fue publicada, y la polémica que suscitó acerca de los beneficios o los daños ocasionados por la ocupación española a la población indígena de América, está realmente alejada de la filosofía de la Ilustración. Tanto los defensores como los detractores de la Conquista declararon que los movían a la polémica razones benévolas y humanitarias, y el debate se estableció más sobre reglas de conducta que sobre filosofía alguna. Sin embargo, el asunto pasó a tener importancia para la Ilustración a partir de la Histoire pbilosopbique et politique des... deux Indes ( $177^{\circ}$ ) del abate Guillaume Raynal. En opinión de los historiadores, el abate Raynal se halla junto a Voltaire, Rousseau y Montesquien entre los precursores intelectuales de la Revolución Francesa. ${ }^{7}$ Aunque la obra de Raynal circuló hasta cierto punto en la América del Sur y aparece citada en algunas revistas después de $\mathrm{x} 8$ 10, nunca llegó a ejercer influencia dominante en el ambiente intelectual de la América del Sur. No obstante, consiguió relacionar el problema histórico del tratamiento que los españoles dieron a los indios con los principios filosóficos de la Ilustración, pues según Raynal el imperio español y la Iglesia Católica Romana se unieron para perpetuar un sistema de despotismo político e intelectual.

Además, leyendo a Raynal, los pensadores sudamericanos pudieron ver el paralelo que existía entre las condiciones para la revolución en la América del Norte y en la del Sur. El editor de El Argos de Chile, por ejemplo, en I8r8 publicó trozos de la obra de Raynal que revelaban esta semejanza para inducir a sus lectores a suscribirse a una traducción local de la obra del mismo abate La Revolución de la América del Norte. Decía el editor:

La analogía que bajo ciertos respecios hay entre la gloriosa insurrección de los norteamericanos y la nuestra, no menos gloriosa y heroica, el mismo sistema de opresión de parte de las metrópolis,

6 Miguel Battlori, S.J., El Abate Viscardo (Caracas, 1953), pp. 306-307.

7 Para más información acerca de la importancia intelectual de Raynal véase: Antonello Gerbi, Viejas polémicas sobre el Nuevo Mundo (Lima, 1944); La disputa del Nuovo Mondo: storia di una polemica, 1750-1900 (Milano, 1955). 
motivos idénticos de queja de parte de los americanos, igual derecho de sacudir el yugo europeo, las reflexiones filosóficas que el autor siembra en aquella obrita, todo, en una palabra, la hace muy recomendable a los ojos del hombre que idolatra el país que lo vio nacer. ${ }^{8}$

Más aún, algunos observadores que notaron una gran diferencia entre el régimen colonial español y el inglés alabaron el humano tacionalismo de este último y condenaron el bárbaro despotismo del primero. Para el patriota venezolano Francisco Javier Yanes, la tradición británica era noble y hontada, la española detestable:

La república de Norte América fue fundada en su origen no por la conquista, sino por las transacciones del pacífico Penn. Los legisladores trabajaron en un siglo de luces; en un país en donde no tenían que luchar y vencer un poder militar, ni limitar una autoridad absoluta, ni tampoco despojar a un clero dominante de su poder, a una nobleza de sus derechos privilegiados, a una multitud de familias de sus fortunas, ni de construir su nuevo edificio sobre despojos cimentados en la sangre.9

Un contraste semejante señalaba $E l$ Censor de Buenos Aires (8 de agosto de I816):

Los ingleses y franceses fueron a puntos insulares o casi despoblados, mientras los españoles plantaron su despotismo militar en continentes variados, cuya población era en tiempo de la conquista, y sigue siendo en el día, más numerosa que la de España. La policía colonial de los unos tendía a estrechar las afecciones de sus remotos compatriotas con leyes útiles y equitativas, costumbres ilustradas, e intereses equilibrados, mientras los otros sólo procuraban asegurar su perpetuo dominio con leyes prohibitivas y por sacrificios continuos a la ambición peninsular, así el americano era tratado como una vaca de que se alimentaba su señor.

Otros escritores sudamericanos, no necesariamente influidos por Raynal, seguían denunciando la política española de mantener a sus

B 11 de junio de 1818.

9 Manual politico del venezolano (Caracas: Academia Nacional de la Historia, 1959). p. 89. 
colonias en la ignorancia y la esclavitud espiritual. Estos escritores no sólo se preocupaban por la triste situación indígena, sino también por toda la población del continente, que incluía a españoles y criollos. Al considerar el dominio español en la América del Sur como un crimen contra la humanidad más que un crimen contra los indios, los escritores encuadraban el problema dentro de los límites de la Ilustración.

En este sentido, las obras más famosas se publicaron en Chile a mediados del siglo diecinueve y fueron: un discurso en la Sociedad Literaria por José Victorino Lastarria [en sus Recuerdos litertrios] y Sociabilidad Chilena ( 1844 ) por Francisco Bilbao. Sin embargo, como veremos, en el primer cuarto de siglo fueron muchos los precursores.

Más importante que la existencia de los cargos contra España por la explotación de sus colonias, y por haber mantenido deliberadamente en la ignorancia a los pueblos de la América del Sur, es la acusación de que el nivel intelectual en la misma España era inferior al del resto del mundo. Es el mismo concepto que incluso algunos españoles del siglo dieciocho se atrevieron a expresar después que la invasión napoleónica produjo cierto grado de libertad intelectual. El Dr. Ramón de Salas, de la Universidad de Salamanca, por ejemplo, documentó con amargura esta acusación en el "Prefacio" a Lecciones de derecbo público constitucional para las escuelas de España:

Los españoles con las mejores disposiciones para las ciencias hemos vivido en la ignorancia de las verdades que más importan al género humano: ¿Y cómo podíamos saberlas, cuando no solamente no se nos enseñaban, sino que se nos privaba con el mayor cuidado de todos los medios de adquirirlas? La policía civil y la policía religiosa, en nada se ocupaban con más celo que en mantenernos en aquella estupidez que es el único apoyo de la obediencia pasiva: y si a pesar de esta vigilancia, de este cuidado en cerrar todos los pasos de la luz, se escapaba algún rayo de ella y penetraba hasta un ciudadano, menos preocupado que los otros; desgraciado de él si trataba de propagarla: los calabozos del estado y de la iglesia hacían pronta y severa justicia del insolente que se atrevía a razonar contra lo que se le mandaba creer y obrar.

' Los intelectuales hispanoamericanos compartieron la opinión de que las universidades, los libros y el pensamiento españoles eran muy inferiores a los del resto de Europa. Estos críticos reconocían que el siglo dieciocho era la época de la Ilustración, pero lamentaban que España 
no hubiera tenido parte alguna en ella. Esta opinión contemporánea a los intelectuales de la colonia, que probablemente sabian más respecto a España que cualquier otro grupo fuera de ella, debe tenerse en cuenta por lo menos tanto como las opiniones de los eruditos del siglo veinte.

El ecuatoriano Eugenio de Santa Cruz y Espejo es un ejemplo temprano del repudio colonial por las normas españolas. En su obra Nuevo Luciano (I779), utiliza a Pedro el Grande de Rusia, símbolo del interés por la ilustración científica y literaria entre los líderes políticos, como apoyo para su crítica:

Para el cultivo de las lenguas, humanidades, matemáticas y demás ciencias y artes, que hizo florecer en Moscovia, le bastó visitar la Inglaterra, la Holanda, la Alemania y la Francia. ¿Qué atractivo singular le pudo empeñar en la visita de la corte y de la nación española?... La España ha estado siempre desacreditada para con los extranjeros; si echan los ojos en la población, la ven desierta; si en la política, baja y doble; si en las letras, bárbara e ignorante; si en la policía, inculta y orgullosa; si en la arquitectura, humilde y vulgarísima, y así en todo lo demás. Pedro el Grande, que, no dudo, estaría en el mismo concepto, o que, si no estuvo, es verosímil se lo sugiriesen y esbozasen en los otros reinos florecientes, ¿tendría mucha ni poca gana de ver a España? ¿De España, de donde salen regularmente a peregrinar por las otras naciones, y a mendigar de ellas luces, los españolitos que logran padres de nacimiento y de alguna comodidad ?10

El locus clasicus de la condena americana a la política colonial española es, probablemente, la Carta dirigida a los españoles americanos del abate Viscardo, publicada originalmente en Londres en el año 1799 en versión francesa. Un investigador chileno que la considera "un libelo contra el gobierno español, en el cual tesume los conceptos despectivos del enciclopedismo francés contra el régimen colonial español", ha alegado que la influencia de este tratado fue insignificante. ${ }^{11}$ No se puede negar, no obstante, que su sentimiento y expresión configuran los del periodismo patriótico que prevaleció durante los veinte años posteriores a su publicación y que en conjunto ejerció sin duda gran influencia. Viscardo consideraba que la historia de las colonias españolas se podía

10 (Quito: Imprenta del Ministerio de Gobierno, 1943), p. 87.

11 Francisco A. Encina, "Gestación de la independencia", Revista cbilena de bistoria y geografia, IXXXIX (1940), 16. 
resumir en cuatro palabras, "ingratitud, injusticia, servidumbre y desolación".12

Menos conocido, pero quizás más importante por su objetividad, es el informe de 18I7 del norteamericano $H$. B. Brackenridge. Tal vez Branckenridge no había leído a Las Casas, pero seguramente tomó contacto con ideas semejantes a las del obispo de Chiapas en conversaciones con intelectuales sudamericanos. ${ }^{13}$

... It was far from the policy of Spain to encourage learning in her colonies, which would only tend to increase the difficulty of governing them, and render the colonists more dissatisfied with their lot. It is certainly true, that as long as they continued in the colonial state, learning would be but of little service to them. When the city of Merrida petitioned for leave to establish a university, in the reign of Charles IV it received for reply, that the king did not tbink proper that information should become general in America. "IIt did not suit the policy of Spain," says the Buenos Ayrean manifesto of independence, "that sages should rise up among us, fearful that men of genius might think of advancing the condition of their country, and of improving the morals and excellent capacities of their countrymen." On a similar occasion the Cabildo of Buenos Ayres, having petitioned for leave to establish a mathematical school, was told that learning did not become colonies. ...Some ministers did not hesitate to declare, that reading and writing was as much as the Americans ought to be permitted to learn. Buerra enumerates a variety of instances where permission was sought in vain, to establish schools for the purpose of more liberal instruction. That it should be necessary at all, to sue for permission of this nature, is a sufficient proof of the infernal policy pursued by Spain, in order to preserve her sway by darkening the human mind. In Santa Fe, chymistry was not permitted to be taught; for what reason it is extremely difficult to comprehend, unless it be the jealously of French literature, which had become very much in request towards the close of the last century, throughout all Spanish America. The polished and immaculate Godoy, thought it wise to issue a decree forbidding the study of the law of nature and nations; (derechos de gente) a prohibition, which

12 Miguel Battlori, op, cit. (Apéndice), Carta derijida, p. 2.

13 Voyage to South America Performed by the Order of the American Government in the Years 1817 and 1818 (Baltimore, 1819), I, 39-40. 
may perhaps be attributed to ignorance of the meaning of the terms. Something of this excessive caution, is doubtless to be ascribed to apprehensions of that flood of light poured upon the world by the American revolution; for it is since that period especially, that Spain has manifested such a disposition to tyrannize over the human mind in America**

Una crítica mucho más vehemente salió de fuentes exclusivamen:e hispanoamericanas. La Gaceta de Buenos Aires, del 5 de julio de I8II, repudió el proyecto de readmisión de los jesuitas como "un insulto a la ilustración de la América".

El artículo de $E l$ Censor de Buenos Aires, que ya hemos citado anteriormente [del 8 de agosto de 1816 ], acusaba a España de haber mantenido a América en una esclavitud ilegal y contratia a la naturaleza, añadiendo que durante trescientos años había prevalecido "un sisiema de gobierno iliberal y destructivo". El artículo recuerda elogiosamente las ideas del barón Alexander von Humboldt, quien consideraba que, si Hispanoamérica había vencido de alguna manera, las dificultades de semejante régimen no fue debido ciertamente a la condescendencia de los

* Se hallaba lejos de la política de España, favorecer la enseñanza en sus colonias, pues ello sólo acarriearia un acrecentamiento de las dificultades para su gobierno, y dejaría a los colonos insatisfechos con su suerte. Resultaba indudablemente cierto que mientras continuasen en situación de habitantes de colonias, la enseñanza les reportaría escasos beneficios. Cuando la ciudad de Mérida solicitó permiso para establecer una universidad, durante el reinado de Carlos IV, recibió por respuesta que el Rey no consideraba apropiado que la información se generalizana en Américd". No convenía a la política de España", dice la Declaración de Independencia de Buenos Aires, "que se cultivaran hombres sabios entre nosotros, temerosos de que los hombres de genio pudieran discurrir acerca del progreso de las condiciones de su pais y el mejoramiento de las costumbres y las excelentes condiciones de sus compatriotas". En una ocasión similar, cuando el Cabildo de Buenos Aires solicitó autorización para establecer una escuela de matemática, se le hizo saber que el estudio no favorecia a las colonias.... Algunos ministros no vacilaron en declarar que leer y escribir era lo más que debía permititse estudiar a los americanos. Buerra enumera una serie de instancias en que en vano fueron solicitados permisos para establecer escuelas con el fin de lograr una instrucción más liberal. Que fuera del todo necesario un permiso de tal especie es prueba suficiente de la terrible politica seguida por España a fin de mantener su dominio mediante la ignorancia. En Santa $\mathrm{Fe}$ no se permitió la enseñanza de química; es extremadamente difícil comprender por qué razón excepto si se considera el recelo hacia el libro francés que había llegado a ser muy solicitado a fines del siglo pasado a lo largo de todo Hispanoamérica. El refinado e impecable Godoy consideró valioso decretar la prohibición del estudio del derecbo natural y de gentes, una prohibición que tal vez debai atribuitse a ignotancia del significado de las palabras. Algo de esta excesiva precaución debe atribuirse sin duda al torrente de luá derramado sobre el mundo por la revolución norteamericana, porque es justamente desde este período que España se mostró propensa a la tiranía intelectual èn América ("Introducción", pp. 39-40). 
opresores, sino "solamente a la naturaleza y genio de los americanos, ayudados por el influjo de su clima, y en consecuencia del ardor con que se han procurado libros para beber el desengaño y la ilustración, a pesar de los estorbos vigilantes del gobierno inquisitorial'. Sin duda alguna, concluye El Censor, "las regiones de América poseídas por ingleses y franceses fueron más libres e ilustradas que las españolas, como lo atestiguan los Estados Unidos'. El Censor no se olvidó de citar el caso del obispo español Francisco de Ortiz, quien había considerado a los indios incapaces de recibir los sacramentos porque, en su opinión, carecían de la facultad de razonar. El artículo también cita un extenso texto acerca de la irracionalidad de los indígenas sacado de la obra contemporánea del botánico español Félix de Azara, Memoria sobre el estado rural del R'́o de la Plata en I801, que puede considerarse como el paralelo argentino de Notes on Virginia de Thomas Jefferson.

El pasaje citado de Humboldt en El Censor es, en realidad, menos favorable respecto a los americanos de lo que aparece en esta paráfrasis. De hecho, Humboldt parecía aceptar, por lo menos en parte, la doctrina. de la degeneración biológica, y atribuía la dureza del mando español tanto a la molicie de los habitantes de las colonias como a la tiranía de la metrópoli. Estaba inclinado a creer, como habían observado muchos otros viajeros anteriores a él "que les Américains sont doués par la nature d'une aménité et d'une douceur de moeurs qui tendent à la mollesse, comme l'énergie de quelques nations européennes dégénère facilement en dureté."14 Las extendidas y profundas reyertas y la falta de organización social en las posesiones españolas fueron atribuidas por Humboldt a los principios políticos que habían gobernado estas regiones desde el siglo dieciséis.

En el número del 4 de mayo de I8I9, escribiendo en La Gaceta de Buenos Aires, vuelve a acusar a España de haber despoblado a América en la conquista inicial y haberla sumergido luego en la ignorancia. Señala, irónicamente, que "los Españoles de la Península temen perder la opinión de crueles y feroces; quieren que la conl tanza se aleje de nosotros para siempre; repiten que el bierro y el fuego son los únicos medios de reconciliar la paz en los establecimientos de América; y lo practican sin escrúpulo, por donde quiera que pueden llevar el error y espanto de sus armas".

Los investigadores modernos a veces citan el Mercurio Peruano como ejemplo del pensamiento liberal tolerado por la administración española. I, 143.

14. Essai politique sur le royaume de la Nouvelle-Espagne (Paris, 1818), 
Según John Tate Lanning, "the Amantes del País published between I79I and 5793 the singular Mercurio Peruano which - with almost as many subscribers as the Hispanic American Historical Review - was dedicated to the dissemination of Enlightenment, especially in fields of pure science less likely to involve theological dispute". 15 Comparemos este juicio con la reacción contemporánea, menos entusiasta, de la Gacketa de Buenos Aires, del 9 de septiembre de 1815 : "El Mercurio Peruano publicó algunos papeles curiosos, mas no habló de política; y no pudiendo sus muy apreciables autores hablar una palabra acerca de los asuntos de más alto y trascendental interés, se vinieron a ver precisados a escribir la historia de la fundación de los monasterios, y en fin, quedaron en silencio".

En las revistas de Chile y de la Argentina es posible hallar buen número de acusaciones semejantes contra el antiintelectualismo español. Los comentarios posteriores del autor del citado artículo de la Gaceta de Buenos Aires son notables, no sólo como diatriba contra la ignorancia española, sino porque además introduce las teorías de la degeneración biológica. Aunque casi todos los habitantes del hemisferio repudiaron el concepto de que la Naturaleza en el hemisferio occidental traía consigo la degeneración de todas las especies vivientes, este escritor aceptó la tesis de la degeneración intelectual y atribuyó esta decadencia intelectual a la dominación española. El trato que dio España a sus colonias, fue "un crimen contra la humanidad", afirmó empleando precoz y significativamente esta expresión. ${ }^{16}$

Las colonias francesas gozaban de todos los libros, de todos los descubrimientos científicos: las británicas disfrutaban de las ventajas del sistema liberal y equitativo de la Metrópoli. ¿Será posible que la Divina Providencia hubiese permitido el descubrimiento del Nuevo Mundo para que millones de hombres viviesen encerrados en una cárcel intolerable? ¿Será posible que este grande acontecimiento viniese a suceder en el tiempo en que se apresuraba a mejorarse la especie humana por sus progresos en las ciencias naturales, por la experiencia de sus extravíos, por el desengaño de sus absurdos antiguos por una masa admirable de luces, para que millones de desgraciados viviesen embrutecidos en eterna ignorancia $e$ infancia?

¿iIgnorancia! dirá alguno cuando teníamos universidades y

15 "The Reception of the Enlightenment in Latin America", in Latin America and the Enligbtenment, Arthur P. Whitaker ed. (Ithaca, 1961), pp. 82-83.

269 de septiembre de 1815 . 
colegios? Pero ¿qué se enseñaba en esas universidades y colegios? No las matemáticas ni el derecho natural y de gentes, no la ciencia de la naturaleza, no las lenguas cultas: sino el blictiris escolástico, la obscuridad de las escuelas, las opiniones de algunos modernos mal analizadas ... en fin una jerga cuyo ridículo está graciosamente descubierto por Almeyda, y tantos otros. Añádase a lo inmenso que hay que decir, la absurda costumbre de enseñar lo que se llamaba ciencia en latín, esto es, en latín corrompido y bárbaro, y ya no se extrañará el que al principio de la gran revolución de España y América se hubiesen hallado tan pocos que tuviesen noticia de los derechos del hombre y del ciudadano, y de los pueblos, de la complicada naturaleza de su libertad, de la distinción de los tres poderes, de la limitación de los gobiernos \& \&. ¡Excelente fruto el de nuestros colegios y universidades!

Reflexionando sobre la miseria de nuestros planes de estudios; sobre la horrorosa Censura a que se sujetaba cuanto quería publicarse, y la calidad de las personas a quienes se cometía dicha censura, sobre lo caro de las impresiones; sobre nuestra carencia de observatorios astronómicos, laboratorios químicos \&, no parece tan extraña la atrevida aserción de de Paw, que dixo que esta America en trescientos años no había producido un hombre capaz de componer un mal libro: la tal asercion es evidentemente falsa, mas no carecía de fundamento.

Una denuncia prácticamente igual surgió de la pluma del distinguido jurisconsulto chileno Manuel de Salas en 1823, quien afirmaba que "la educación científica de la época española no dividía sus frutos sino entre eclesiásticos y abogados". Por consiguiente, los estudios que requieren un conocimiento amplio y general estaban en manos de ministros de la Iglesia y defensores de causas privadas. $Y^{\prime}$ estas profesiones, según Salas, no tienen relación alguna con la ciencia del gobierno, la economía, el comercio y todos los otros factores de los que depende la prosperidad de una nación. ${ }^{17}$

La mejor y la más razonada crítica del dominio español es, según Germán Arciniegas, el Memorial de agravios (I809) del escritor colombiano Camilo Torres. ${ }^{18}$ Respecto a la Ilustración, Torres negó rotundamente que América fuera superior a las provincias de España; ni si-

17 Mercurio de Chile, 11 de abril de 1823, recopilado en Escritos de don Manirel de Salas (Santiago, 1914), III, 34-411.

$18 \mathrm{El}$ continente de siete colores (Buenos Aires, 1965), p. 387. 
quiera cabían pretensiones de igualdad. Pero toda la culpa recaía sobre el gobierno despótico, enemigo de la Ilustración. ¿Cómo podían esperar las colonias algún progreso en las humanidades - se preguntaban cuando no se había hecho nada más que poner obstáculos en el camino del conocimiento? Según lo veía Torres, la libertad de prensa había sido limitada severamente; el estudio de la filosofía se había reducido a una jerga metafísica; y el estudio del derecho natural y de gentes había sido completamente prohibido. La "bárbara crueldad del despotismo" hizo de este último el "enemigo de Dios y de los hombres". 19

Cuando en la Argentina se turo noticia del intento napoleónico de regreso al poder en 1815, y de las medidas del gobierno español "contra los Afrancesados y los Liberales", la Gaceta de Buenos Aires del 5 de agosto de I8I5, vio en esta ola de reacción un retorno a la "densa noche de ignorancia" que siempre había envuelto al pueblo español", iluminada únicamente por la luz melancólica de las hogueras inquisitoriales":

Cuando las luces se extienden hasta la Rusia, y la Turquia; cuando los inmensos trabajos de los Sabios, las meditaciones profundas, el genio analítico y matemático, el examen y lectura de los más antiguos y recónditos monumentos, el estudio de las lenguas orientales... han descubierto tantos errores, desenmascarado a las imposturas, hallado tantas verdades; en España se leerán solamente los librotes en que estén consignados todos los absurdos, todos los delirios! Desgraciados los hombres que piensan en la España! Pero ellos emigran dejando a su patria infeliz en su eterno letargo, y en su forzosa miseria. Podemos formarnos alguna idea del infortunio de aquellos literatos, poniéndonos en lugar suyo. Si después de que hemos gustado los vislumbres de la libertad, se nos suprimiese la libertad del pensamiento, y de la lectura, si la fuerza nos despojase de los libros más preciosos, si la superstición y la ignorancia estúpida prevaleciesen y se armasen contra los principios que no entienden... ¿cuál sería nuestra desesperación y furor? No suspiraríamos por una patria para el pensamiento, por un asilo contra el azote más horrible del género humano! No preferiríamos los áridos desiertos donde hallásemos a la pacífica naturaleza sin los ilusos que la deshonran, sin los impostores que la desfiguran, sin los fanáticos que la destruyen!

Poco después de proclamada la independencia de la República del

19 Reimpreso (Colombia, 1960), p. 388. 
Plata, los alumnos de la primera escuela organizada en Buenos Aires bajo el nuevo régimen exhibieron sus adelantos intelectuales en un examen público. Todos los altos funcionarios del gobierno estuvieron presentes en el acto, y también el obispo. Los estudiantes fueron examinados, principalmente en matemática y gramática; de un total de veinte secciones, sólo una estaba dedicada a doctrina cristiana. Un escritor, en la Gaceta del I5 de noviembre de $18 \mathrm{II}$, se maravillaba de "los efectos de una revolución que es obra de las luces, y de la filosofía". Según sus datos, este acontecimiento era

el primero en su especie, no solamente en la capital, aún tal vez en todo el reino. ...La solución exacta a las preguntas demostraron que la juventud educada bajo una autoridad tutelar produciría frutos que fuesen la riqueza de nuestro suelo. ... Los ancianos oían como nueva invención este acto, y los jóvenes veían con indignación e increpaban la conducta de una política mezquina, que los privó no solamente de una educación útil, mas también les cerró las instituciones que algunos amantes de la humanidad habian establecido. ¡Infelices los hombres que tienen la desgracia de ser colonos; ellos son privados hasta de iluminar su razón!

Otro contraste entre la situación anterior y posterior a la independencia se puede leer en las Memorias bistórico-politicas del patriota boliviano Vicente Payos Kanki.20 Bajo la monarquía española la cultura oficial, basada en la filosofía escolástica, había ahogado en todas partes "toda atención a la moralidad, al dogma y la jurisprudencia". En las colonias de la América del Sur:

los estudios que en ellos se cursaban, en la mayor parte, era la filosofía de Aristóteles que había tiranizado por largos siglos la república de las letras, y aunque despreciada y expulsada de casi toda la Europa, conservaba la veneración de las escuelas de España y América, y se oían por tanto en estas Universidades aquellas voces bárbaras, aquellas sentencias oscurísimas y los raciocinios vanos y sutiles que hacían la gloria y delicia de sus creyentes. La jurisprudencia también tenía sus escolásticos que la extraviaron hacia los laberintos del árbitro y de la opinión que hacían eviternos los procesos civiles. Era desconocido el estudio de sus orígenes; ni tenía principios fijos, porque no se enseñaba el derecho natural.

20 (Londres, 1834), pp. 338-339. 
Después de la Revolución, en cada ciudad se ha éstablecido una Universidad: la enseñanza se ha depurado de los vicios del escolasticismo; la fuerza de la demostración sucede a la sutileza del silogismo. Procúrase ya que el estudio de la física se apoye sobre la experiencia y el cálculo se perfecciona; y nacerán con él las demás ciencias de su jurisdicción, como la química, la mineralogia y la metalurgia, la historia natural y la botánica. Llámanse de Europa profesores que instruyan a los jóvenes en estos ramos, al mismo tiempo que se llevan libros, se transportan aparatos, y se anima y se facilitan los medios de trasladarse a cuantos lleven sus conocimientos científicos a todas las partes del Nuevo Mundo.

Si estas ciencias son tan útiles y necesarias para desenvolver $\mathrm{y}$ aprovechar de las riquezas naturales del país, hay otra más importante y la que era enteramente desconocida: la ciencia de gobierno; su fin es apoderarse de los conocimientos morales y naturales, haciendo de ellos aplicación provechosa... La libertad de imprenta, el juicio por jurados en las causas que nacen de su abuso, la abolición de la esclavatura, la prohibición absoluta del tráfico de los negros. La seguridad y garantía de las propiedades de los extranjeros, el ejercicio libre y público de su religión, los varios establecimientos de educación elemental y científica, arreglados por las mejores normas de la Europa ilustrada. Este es el sinopsis de las instituciones sociales de la República de la Plata...

Una denuncia aún más vigorosa del despotismo intelectual del dominio español fue la del director de la Biblioteca Nacional de Lima en ocasión de su inauguración. Dijo: "Convencido el gobierno español de que la ignorancia es la columna más firme dell despotismo, puso las más fuertes trabas a la ilustración americana, manteniendo el pensamiento encadenado para impedir que adquiriese el conocimiento de su dignidad".21

Es cierto que los ataques sudamericanos al sistema educativo español en gran medida coincidieron con el movimiento de independencia politica. Por ello, algunos investigadores podrán sentirse inclinados a atribuirlos, a la enemistad natural de las colonias hacia la metrópoli o la necesidad psicológica que las naciones recientemente independientes tenían de afirmar sú nacionalismo cultural frente a la madre patria. No obstante, estos ataques no pueden ser considerados totalmente incorrectos o exagera-

21 Citado en Germán Arciniegas, op. cit., p. 366. 
dos simplemente porque sirvieron de propaganda emocional. Durante el movimiento previo a la guerra de independencia de la América del Norte, los ataques a los programas políticos y económicos de la metrópoli eran tan duros y demoledores como los de América del Sur contra España, pero no hubo crítica alguna al sistema de educación británico ni quejas por falta de divulgación de las ideas. La Ilustración en Inglaterra fue acompañada por la llustración en Norteamérica. Es posible que floreciera unos años más tarde en el Nuevo Mundo, pero no fue porque se intentara ahogarla o exterminarla.

La actitud de la IJustración hispanoamericana hacia su herencia española representa un importante capítulo en la historia de las ideas. Los pensadores de las jóvenes repúblicas condenaron firmemente las universidades controladas por los españoles por haber perpetuado planes de enseñanza basados en el escolasticismo y por su total incapacidad para proporcionar a sus estudios una base científica que se incluyera en las ciencias políticas. Esta crítica declarada demuestra que había una diferencia considerable en magnitud y características entre la Ilustración en la España del siglo dieciocho y la de América del Sur durante la época de la Revolución Liberal. Aun las voces más progresistas de España eran temerosas y débiles comparadas con las de los atrevidos espíritus de Sudamérica. Los esfuerzos de algunos investigadores modernos para probar la existencia de un espíritu vigoroso en la ilustración de la España del siglo dieciocho no pueden conciliarse con la general condena que los escritores sudamericanos han hecho de la enseñanza durante la colonia.

La más notable caracierística que sus declaraciones revelan es ávida necesidad y anhelo de instrucción y libertad intelectual. Que denunciaran a España por privar a América de desarrollo intelectual —algunos bajo riesgo de represalia personal- revela la gran importancia de la Ilustración en una parte del mundo donde su influencia no ha sido apreciada suficientemente.

University of Illinois

A. OWen Aldridge 
